\title{
SLIDING-MODE CONTROL FOR THE DECOUPLED POWER CONTROL OF DOUBLY-FED INDUCTION GENERATOR
}

\author{
Filipe S. Trindade*, Alfeu J. Sguarezi Filho**, Rogério V. Jacomini**, José A. T. Altuna** and Ernesto Ruppert* \\ * School of Electrical and Computer Engineering of State of Campinas - UNICAMP - Campinas, Brazil \\ **Centro de Engenharia, Modelagem e Ciências Sociais Aplicadas da Universidade Federal do ABC - UFABC - Santo André, Brazil \\ fstrindade@gmail.com, alfeu.sguarezi@ufabc.edu.br, rogeriovj@yahoo.com.br and ruppert@fee.unicamp.br
}

\begin{abstract}
This paper proposes a decoupled control of active and reactive power for doubly-fed induction generators (DFIG) by using the rotor current control loop and sliding mode control (SMC). In order to decouple the active and reactive power generated, stator-fluxoriented vector control is applied. The sliding mode control strategy proposes is based on two sliding modes plus PI controllers whose main advantage is the easy implementation. Simulation and experimental results are presented to validate the proposed control scheme for a 2 kW DFIG during stator active and reactive power steps and rotor speed variation. During transient operation it is checked good dynamic response.
\end{abstract}

Keywords - Doubly-fed induction generator, Flux orientation, Vector control, Power control, Sliding mode control.

\section{LIST OF SYMBOLS}

$R_{1}, R_{2} \quad$ Stator and rotor resistances.

$L_{1}, L_{2} \quad$ Stator and rotor self inductances.

$L_{m} \quad$ Mutual inductance.

$\omega_{1} \quad$ Synchronous angular speed.

$\omega_{\text {mec }} \quad$ Mechanical angular speed.

$\theta_{s}, \theta_{r} \quad$ Stator flux vector and rotor angles

$P, Q \quad$ Active and reactive power.

$\bar{v} \quad$ Voltage space vector.

$\bar{i} \quad$ Current space vector.

$\bar{\lambda} \quad$ Flux linkage space vector.

Superscripts

* Reference value

$\begin{array}{cl}\text { Subscripts } & \\ 1,2 & \text { stator and rotor, respectively } \\ \alpha, \beta & \begin{array}{l}\text { direct- and quadrature-axis expressed in the } \\ \text { stationary reference frame } \\ \text { direct- and quadrature-axis expressed in the } \\ \text { synchronous reference frame } \\ \text { direct- and quadrature-axis expressed in the } \\ \text { rotor reference frame }\end{array}\end{array}$

\section{INTRODUCTION}

The renewable energy systems have attracted interest due to the increasing concern about the emission of carbon dioxide and other pollutant emissions. One renewable source who has great attention is the wind energy.

Artigo submetido em 24/01/2013. Primeira revisão em 30/06/2013, segunda revisão em $25 / 08 / 2013$. Aceito para publicação em $15 / 02 / 2014$, por recomendação do Editor Henrique A. C. Braga.
DFIG based wind turbines have been used for this kind of electric energy generation, since this kind of asynchronous machine is a cost effective, efficient and reliable solution [1]. The typical topology of a DFIG based wind turbine connected to the grid is shown on Figure 1.

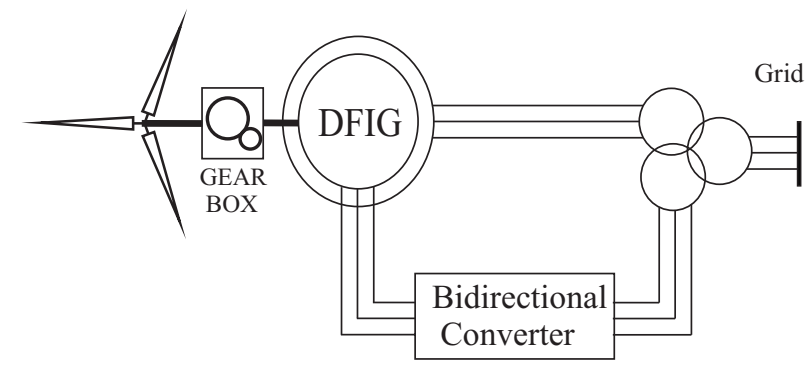

Fig. 1. Configuration of DFIG connected direct to the grid.

In this configuration the stator of the generator is connected directly to the grid. The great part of the generated power is delivered to the grid by the stator of the DFIG. The rotor is connected to the grid by using a bidirectional converter. The converter allows the power flow between the rotor of the generator and the grid [2].

The field-oriented control used in induction motor control [3] is also widely used in control of DFIG. The control of the wind turbine system can be based on either stator-fluxoriented vector control [4] or stator-voltage-oriented vector control [5]. The scheme decouples the rotor current into active and reactive power components and, with a rotor current controller, the power control is achieved. Some investigations using PI controllers that creates rotor current references to the inverter from active and reactive power errors or in-seriesPI controllers that results in rotor voltage references have been presented by $[4,6,7]$. PI controllers are also applied to DFIG under grid voltages dips conditions $[8,9]$. The problems in using PI controllers are the tunning, the crosscoupling of DFIG terms and it's slow response in small hydroelectric station applications. To avoid the use of PIs, in [10] proposes controllers for field-oriented control (FOC) based on the dynamic modeling of the DFIG. However, this strategy presents a high computational cost and only simulation results was presented.

The Sliding Mode Control (SMC) strategy is a variable structure control method. It is an alternative to the classic control theory for a noncontinuous control implementation $[11,12]$. This kind of control has a switching characteristic, which becomes an interesting process when applied to switching power converters [13]. In [14] was proposed a sliding mode approach for direct torque control of sensorless induction motor drives. Regarding the control 
of DFIG, power regulation or torque regulation techniques, such as direct torque control (DTC) $[14,15]$, direct power control(DPC) $[16,17]$ has been investigated displaying excellent dynamic performance. A interesting method of a cutting-in no-load application for field-oriented control (FOC) has been presented in [18]. Nevertheless, the use of SMC plus PI controllers did not apply to the FOC for power control of DFIG till this moment. However, many of these techniques present variable switching frequency (which complicates the AC filter design), current distortion or they are very dependent on the machine parameters. A nonlinear controller based on sliding mode, described in the stationary coordinate system is implemented by [19]. However, the control objective is the operation under voltage sag and the controller design is developed from the dynamic equations of the DFIG, including terms representing the uncertainties and disturbances in the network.Hence, the project of this controller is very hard and it did not use SMC plus PI controllers.

This paper proposes a new alternative power control scheme for DFIG using sliding mode controllers with stator-fluxoriented vector control. The SMC proposed is based on two sliding modes plus PI controllers, one of its main advantages is the low computational cost for implementation, good response dynamics of power and excellent performance during speed variation. The output of SMC generates the reference values of d- and q-axis rotor voltages, where d-axis is generated by reactive power law and q-axis by the active power control law, where are transformed to the coordinate system fixed on the rotor and used in space vector modulation (SVM). The SMC strategy combined with the SVM has excellent performance in terms of low power ripple. Simulation and experimental results are presented to validate the proposed control scheme.

\section{MACHINE MODEL}

The doubly-fed induction generator model in the synchronous reference frame was given by [20] and it is described by the following equations:

$$
\begin{gathered}
\vec{v}_{1 d q}=R_{1} \vec{i}_{1 d q}+\frac{d \vec{\lambda}_{1 d q}}{d t}+j \omega_{1} \vec{\lambda}_{1 d q} \\
\vec{v}_{2 d q}=R_{2} \vec{i}_{2 d q}+\frac{d \vec{\lambda}_{2 d q}}{d t}+j\left(\omega_{1}-N P \omega_{m e c}\right) \vec{\lambda}_{2 d q}
\end{gathered}
$$

where the relationship between magnetic fluxes and currents are done by:

$$
\begin{aligned}
& \vec{\lambda}_{1 d q}=L_{1} \vec{i}_{1 d q}+L_{M} \vec{i}_{2 d q} \\
& \vec{\lambda}_{2 d q}=L_{M} \vec{i}_{1 d q}+L_{2} \vec{i}_{2 d q}
\end{aligned}
$$

and generator's active and reactive power are done by:

$$
\begin{aligned}
& P=\frac{3}{2}\left(v_{1 d} i_{1 d}+v_{1 q} i_{1 q}\right) \\
& Q=\frac{3}{2}\left(v_{1 q} i_{1 d}-v_{1 d} i_{1 q}\right)
\end{aligned}
$$

The subscripts 1 and 2 represent, respectively, the parameters of stator and rotor; $\omega_{1}$ represents the synchronous speed; $\omega_{m e c}$ represents the mechanical speed of the generator; $R_{1}$ and $R_{2}$ represent per phase electrical resistance; $L_{1}, L_{2}$ and $L_{m}$ represent windings proper and mutual inductances; $\vec{v}$, $\vec{i}$ and $\vec{\lambda}$ represent, respectively, the voltage, the current and the flux space vector; and NP represents number of pole pairs.

The proposed power control aims independent stator active $P$ and reactive $Q$ power control by means of a rotor current regulation. For this purpose, $P$ and $Q$ are represented as functions of each individual rotor current. To achieve this objective, the stator-flux-oriented vector control method decouples the $d q$ axis and makes $\lambda_{1 d}=\lambda_{1}=\left|\vec{\lambda}_{1 d q}\right|$. Thus, in steady state (3) becomes

$$
\begin{gathered}
i_{1 d}=\frac{\lambda_{1}}{L_{1}}-\frac{L_{M}}{L_{1}} i_{2 d} \\
i_{1 q}=-\frac{L_{M}}{L_{1}} i_{2 q}
\end{gathered}
$$

Similarly, the stator voltage becomes $\vec{v}_{1 d}=0$ and $v_{1 q}=v_{1}$ $=\left|\vec{v}_{1 d q}\right|$. Hence, the active (5) and reactive (6) powers can be calculated by using the Equations (7) and (8)

$$
\begin{gathered}
P=-\frac{3}{2} v_{1} \frac{L_{M}}{L_{1}} i_{2 q} \\
Q=\frac{3}{2} v_{1}\left(\frac{\lambda_{1}}{L_{1}}-\frac{L_{M}}{L_{1}} i_{2 d}\right)
\end{gathered}
$$

The stator current can be computed by using the rotor current. Consequently, this principle can be used on active and reactive power control by controlling the currents in the rotor side when the the stator of the generator is connected directly to the grid.

\section{SMC APPLIED TO THE DFIG POWER CONTROL}

The essential idea of traditional SMC control algorithms is to enforce the system mode to slide along a predefined sliding surface of the system state space [11]. Once the state of the system reaches the sliding surface, the structure of the controller is adaptively changed to slide the state of the system along the sliding surface. Hence, the system response depends only on the predefined sliding surface and remains insensitive to variations of system parameters and external disturbances. However, such insensitivity property is not guaranteed before sliding mode occurs, resulting in the loss of the robustness during the reaching phase. Furthermore, in order to reduce the chattering, the sign function of SMC is often replaced by saturation function in practical implementations [21].

The proposed strategy uses the sliding mode controller and the stator-flux-oriented control to regulate the rotor currents and the active and reactive power based on (9) and (10).

The error between the current references and the measured values are used to obtain the sliding surface as

$$
e_{i 2 d}=i_{2 d r e f}-i_{2 d}
$$




$$
e_{i 2 q}=i_{2 q r e f}-i_{2 q}
$$

where $i_{2 d}$ and $i_{2 q}$ are the rotor currents calculated on the $d q$ referential frame. $i_{2 d r e f}$ and $i_{2 q r e f}$ are the rotor current references in the $d q$ reference frame given by

$$
\begin{gathered}
i_{2 q r e f}=-\frac{2 P_{r e f} L_{1}}{3 v_{1} L_{M}} \\
i_{2 d r e f}=-\frac{2 Q_{r e f} L_{1}}{3 v_{1} L_{M}}+\frac{\lambda_{1}}{L_{M}}
\end{gathered}
$$

The sliding surface $S$ can be defined as

$$
S=\left[\begin{array}{l}
s_{1} \\
s_{2}
\end{array}\right]=\left[\begin{array}{l}
e_{i 2 d}+c_{i 2 d} \frac{d}{d t}\left(e_{i 2 d}\right) \\
e_{i 2 q}+c_{i 2 q} \frac{d}{d t}\left(e_{i 2 q}\right)
\end{array}\right]
$$

where $c_{i 2 d}$ and $c_{i 2 q}$ are constants defined taking into account the desirable dynamic response for the system.

According to the Equations (13) and (14), the rotor current $d$ component is responsible for the reactive power control and, the rotor current $q$ component, is responsible for the active power control. By this way, the control objective is to make the system state go to the equilibrium point defined on the origin of the sliding surface $(S=0)$, where the errors and their derivatives are zero, ensuring that the states reach their references.

Based on [14], for active and reactive power control by regulating rotor currents, the rotor voltage references are given by

$$
\begin{aligned}
& v_{2 d r e f}=\left(K_{P i 2 d}+\frac{K_{I i 2 d}}{s}\right) \cdot \operatorname{eval}\left(s_{1}\right) \\
& v_{2 q r e f}=\left(K_{P i 2 q}+\frac{K_{I i 2 q}}{s}\right) \cdot \operatorname{eval}\left(s_{2}\right)
\end{aligned}
$$

where $K_{P i 2 d}$ and $K_{P i 2 q}$ are the proportional gains and $K_{I i 2 d}$ and $K_{I i 2 q}$ are the integral gains as for a PI controller; $v_{2 d r e f}$ and $v_{2 q r e f}$ are rotor voltage references on $d q$ reference frame; and, eval $\left(s_{1}\right)$ and $\operatorname{eval}\left(s_{2}\right)$ are evaluation functions that determine the switching behavior of the controller once the responses reach the sliding surface. The use o PI controllers allows constant switching operation and increase the stability of the controller [14].

The eval function can be simple as the signal function. However in this case, it was used a saturated linear function, as given by

$$
\operatorname{eval}\left(s_{n}\right)=\left\{\begin{array}{cl}
\max , & \text { if } K . s_{n} \geq \max \\
K . s_{n}, & \text { if } \min <K . s_{n}<\max \\
\min , & \text { if } K . s_{n} \leq \min
\end{array}\right.
$$

where $n$ can be 1 or 2 and $k$ is a proportional gain. So $k$ is adjusted based on the sliding surfaces $s_{1}$ and $s_{2}$ presented in Eq. (15).

The gains of the PI controllers and the gain $k$ of eval function can be design carefully in order to guarantee the stability of the system [22].

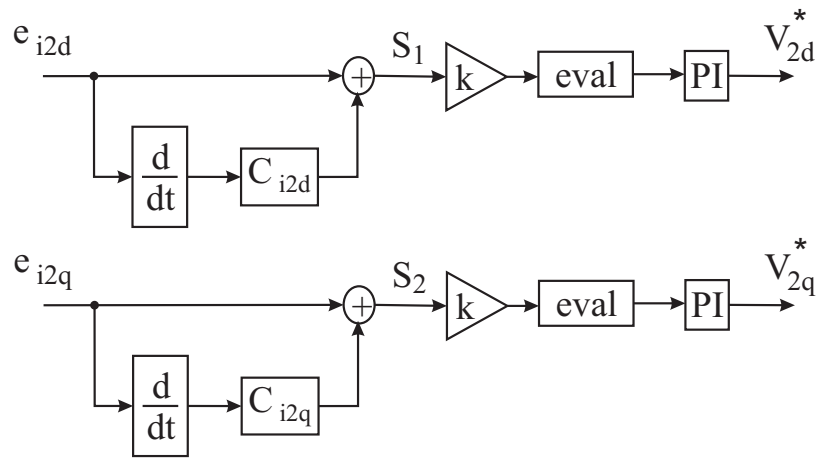

Fig. 2. The Sliding Mode Controller for DIFG power control.

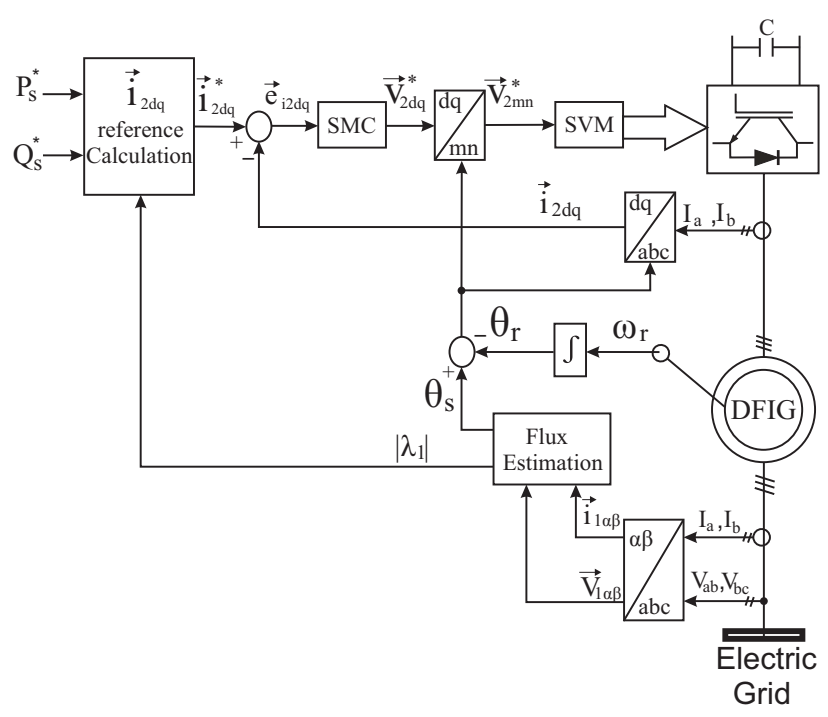

Fig. 3. Configuration of DFIG connected direct to the grid with a Sliding Mode Controller.

\section{A. Description of the implemented control system}

The block diagram of the proposed control scheme is shown in Figure 3 and in Figure 2 is shown the details of the SMC block.

The desired rotor voltage in the rotor $m n$ reference frame generates pulse width modulation (PWM) switching signals for the rotor side using either space vector modulation (SVM) that is given by $v_{2, m n}^{*}=v_{2, d q}^{*} e^{\theta_{s}-\theta_{r}}$. The stator currents and voltages, rotor speed and currents are measured to stator flux position $\theta_{s}$ and magnitude $\lambda_{s}$ and synchronous frequency $\omega_{1}$ estimation.

The flux estimation is obtained using the following equation

$$
\vec{\lambda}_{1, \alpha \beta}=\int\left(\vec{v}_{1, \alpha \beta}-R_{1} \vec{i}_{1, \alpha \beta}\right) d t
$$

and the flux position by using (19) as

$$
\theta_{s}=\arctan \left(\frac{\lambda_{1 \beta}}{\lambda_{1 \alpha}}\right)
$$

The flux estimation using (19) can be degraded due to quantizations errors or dc levels on measured currents or voltages signals. A interest method for stator flux estimation can be made by using $[23,24]$. 
The synchronous speed $\omega_{1}$ estimation is given by

$$
\omega_{1}=\frac{d \theta_{1}}{d t}=\frac{\left(v_{1 \beta}-R_{1} i_{1 \beta}\right) \lambda_{1 \alpha}-\left(v_{1 \alpha}-R_{1} i_{1 \alpha}\right) \lambda_{1 \beta}}{\left(\lambda_{1 \alpha}\right)^{2}+\left(\lambda_{1 \beta}\right)^{2}}
$$

To maintain the $S V M$ in the linear zone of operation, the rotor voltage $\bar{v}_{2, m n}^{*}(k)$ is limited as follows

$$
\begin{gathered}
\left|\bar{v}_{2, m n}^{*}(k)\right|=\sqrt{v_{2 m}^{* 2}(k)+v_{2 n}^{* 2}(k)} \\
\theta(k)=\arctan \frac{v_{2 n}^{*}(k)}{v_{2 m}^{*}(k)} \\
\text { if }\left|\bar{v}_{2, m n}^{*}(k)\right|>=v_{2, \max } \text { then }\left|\bar{v}_{2, m n}^{*}(k)\right|=v_{2, \max } \\
v_{2 m}^{*}(k)=\left|\bar{v}_{2, m n}^{*}(k)\right| \cos [\theta(k)] \\
v_{2 n}^{*}(k)=\left|\bar{v}_{2, m n}^{*}(k)\right| \sin [\theta(k)]
\end{gathered}
$$

where $v_{2, \max }$ is the maximum rotor phase voltage that the converter can produce. Hence, the power electronic converter provides the maximum voltage $\left(v_{2, \max }\right)$ is necessary a dc link voltage given by

$$
V_{D C}=\frac{\sqrt{3} \times v_{2, \max }}{\left(N_{s} / N_{r}\right) \times m}
$$

where $m=1.25$ is the modulation index of SVM and $\left(N_{s} / N_{r}\right)$ is the stator/rotor turns ratio of the DFIG.

\section{SIMULATION AND EXPERIMENTAL RESULTS}

The SMC strategy proposed has been simulated using the Simulink on a $2.2 \mathrm{~kW}$ DFIG, whose nominal values are given in Appendix. To validate the simulation results, the SMC strategy is also applied to a DSP TMS320F2812 platform. The digital implementation of the controller are made by using an zero-order-holder discretization and delay is neglected due the fact the frequency of the system is slower than the frequency of the digital implementation [10].The rotor windings are fed by a three-phase voltage source inverter with with insulatedgate bipolar transistors (IGBTs) and the DFIG is driven by a DC motor. The rotor voltage commands are modulated by using symmetrical space vector PWM and the switching frequency is $5 \mathrm{kHz}$. The DC bus voltage of the inverter is 120 $\mathrm{V}$. The encoder resolution is 3800 pulses per revolution. The experimental setup is shown in Figure 4. System parameters, including control loop parameters that are designed by using simulations of the systems are shown in Appendix .

\section{A. Constant Speed Operation}

Firstly, the generator operates in the subsynchronous mode, driven in a constant speed of $1350 \mathrm{rpm}$ (75\% of synchronous speed of the DFIG) and it was tested with various active and reactive power steps of references. The controller responde for these tests are shown in Figure 5(a). The initial active power and the power factor references were $-2 \mathrm{~kW}$ and +1 , respectively. The active power and the power factor references were changed from $-2 \mathrm{~kW}$ to $-1 \mathrm{~kW}$ and from +1 to -0.85 (capacitive) at $400 \mathrm{~ms}$, respectively. Finally, at $700 \mathrm{~ms}$, the active power reference was changed from $-1 \mathrm{~kW}$ to $-1.5 \mathrm{~kW}$

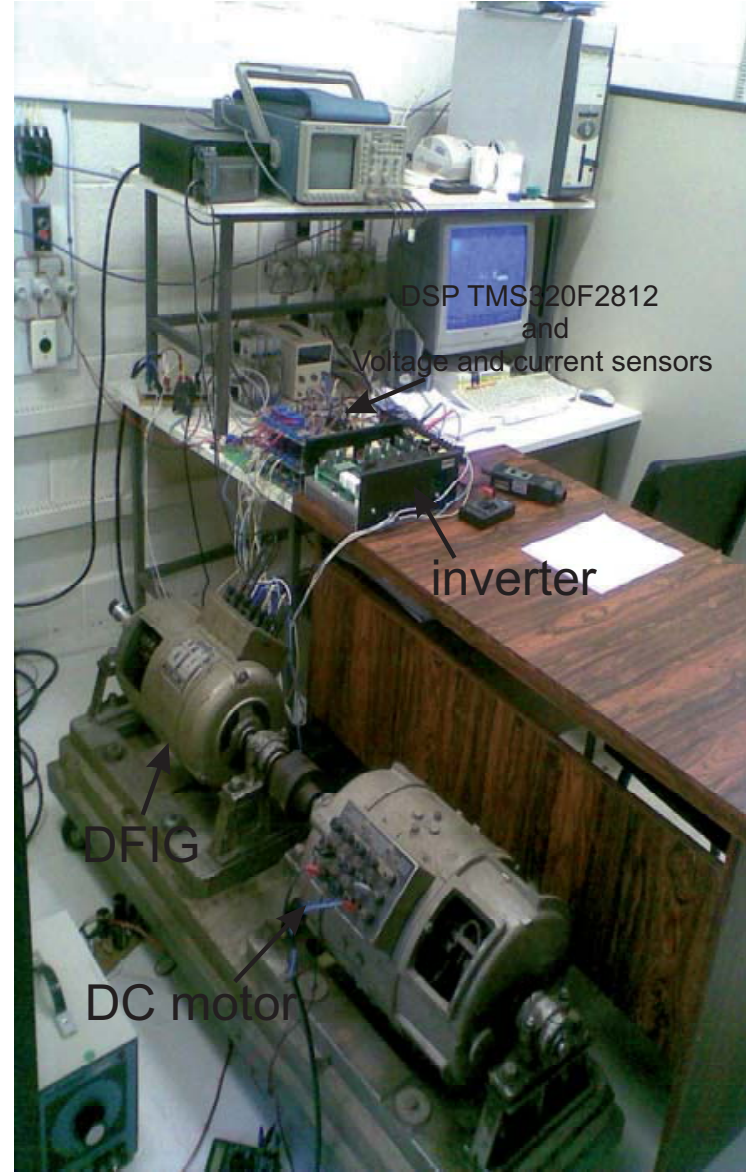

Fig. 4. Experimental setup for power control implementation.

and, the power factor, from -0.85 to +0.85 (inductive). It can observed that during the changes in the power references the SMC strategy generates the required control voltage $\left(v_{2 d}^{*}\right.$ and $v_{2 q}^{*}$ ) from the errors between the references and actual values of the d-q rotor current components. So, the controller allows time response has a few milliseconds without overshoot and zero null steady state error. Figure 6 shows the transient of stator power in detail when the active power and the power factor references changed from $-2 \mathrm{~kW}$ to $-1 \mathrm{~kW}$ and from +1 to -0.85 (capacitive), respectively. Again, the results shows the good performance of the proposed controller. The dq components of the rotor current for this test is shown in Figure 5(b) and it shows that the rotor current reach their references. The rotor current in $\alpha \beta_{r}$ and the phase $a$ stator current and voltage during this test are shown in Figs. 5(c) and 7 , respectively.

\section{B. Variable Speed Operation}

During this test, the generator was driven with a speed profile that varies from $1625 \mathrm{rpm}$ (subsynchronous) to 1975 rpm (supersynchronous) and it was tested with various active and reactive power steps (Figure 8(a)) as performed in previous test. It can be seen that even in variable speed operation the controller is able to act to give a quick response of active and reactive power without overshoot and null steady state error, similarly to the previous test. The d-q components of the rotor current and the rotor current in $\alpha \beta_{r}$ during this test 

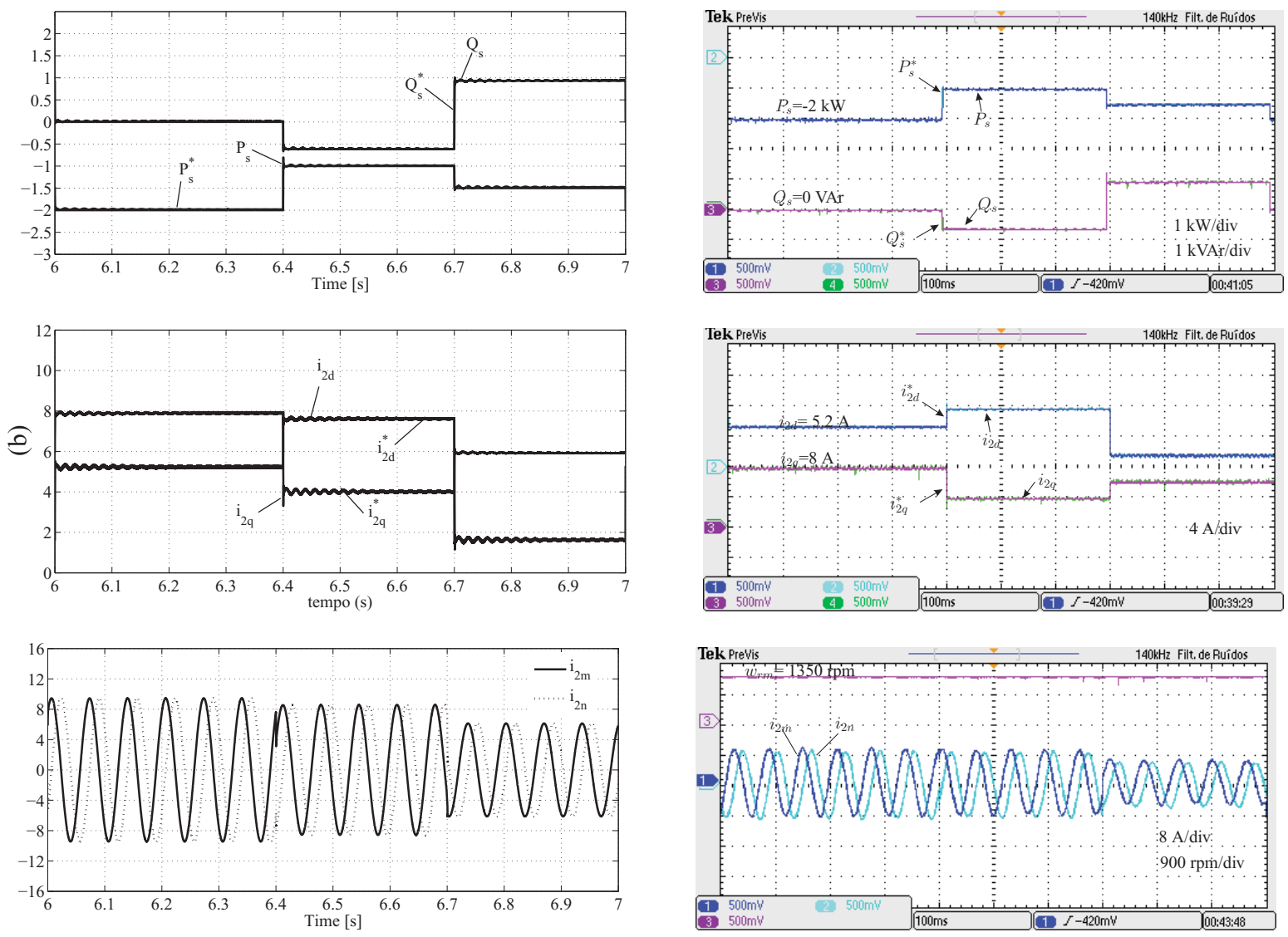

Fig. 5. Simulation and experimental results during tests of various active and reactive power steps in fixed speed operation. (a) Active and reactive power [kW and kvar]. (b) Synchronous d-q axis rotor current [A]. (c) Rotor $\alpha_{r}-\beta_{r}$ axis rotor current and rotor speed [A and rpm].

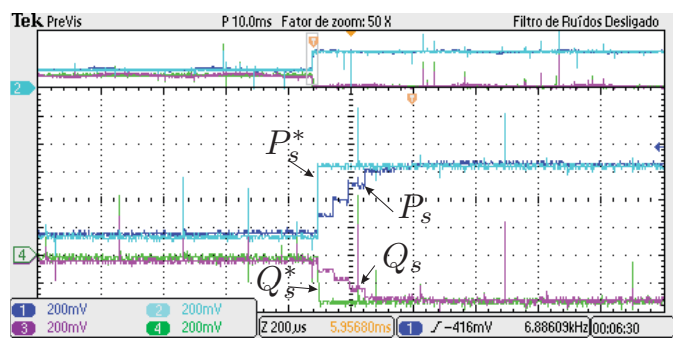

Fig. 6. Zoom of the step response for active power and the power factor references changed from $-2 \mathrm{~kW}$ to $-1 \mathrm{~kW}$ and from +1 to -0.85 (capacitive), respectively.

are shown in Figs. 8(b) and 8(c), respectively.

\section{CONCLUSION}

This paper proposed a SMC applied to the DFIG power control. The rotor voltage is calculated by SMC controller by using slides surfaces based on the rotor current errors, eval functions and PI controllers. Hence, this control technique allows that the power and rotor current reach the references and constant switching operation. Simulation and experimental results have shown satisfactory performance of the controller due to the fast dynamic response in the presented tests with constant and variable rotor speeds. The SMC during these tests has resulted in good responses, with minor steady

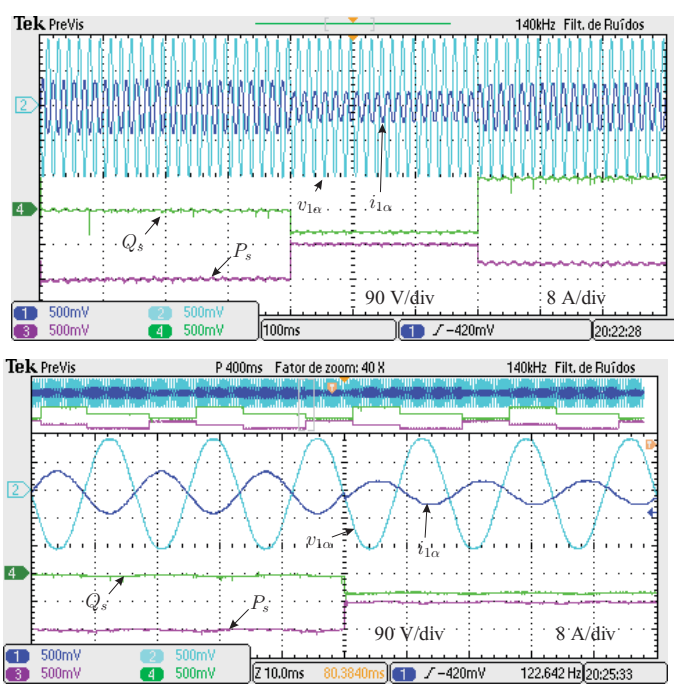

Fig. 7. Stator voltage and current during the step response in fixed speed operation.

state error and overshoot. Hence, it was concluded that the SMC strategy can be used in the power control of the DFIG. 

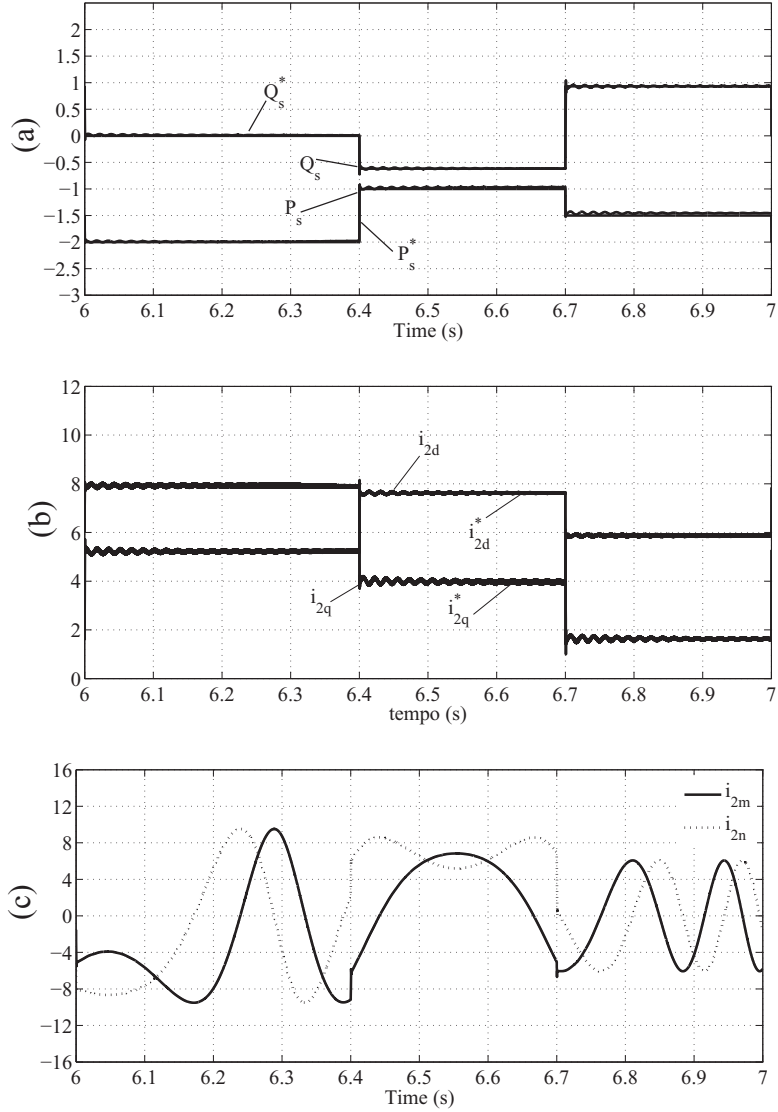
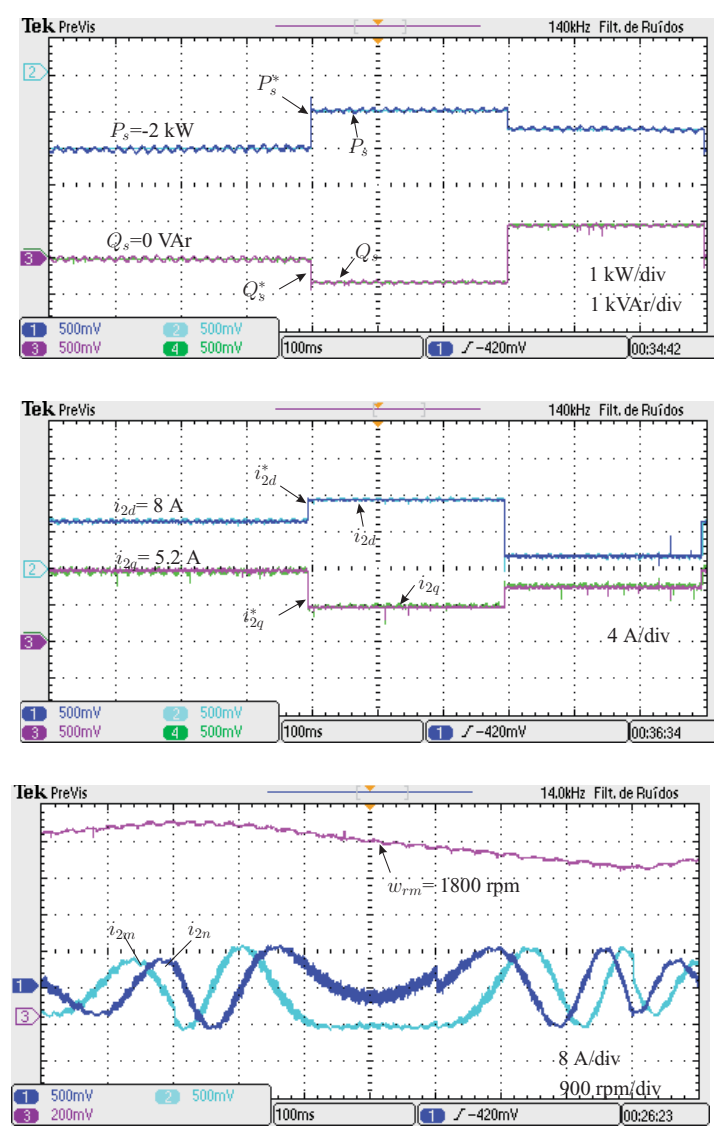

Fig. 8. Simulation and experimental results during tests of various active and reactive power steps in variable speed operation. (a) Active and reactive power [kW and kvar]. (b) Synchronous d-q axis rotor current [A]. (c) Rotor $\alpha_{r}-\beta_{r}$ axis rotor current and rotor speed [A and rpm].

\section{APPENDIX}

Doubly-fed induction generator parameters: $R_{1}=1.2 \Omega$; $R_{2}=0.8 \Omega ; L_{m}=0.092 \mathrm{H} ; L_{l 1}=0.00618 \mathrm{H} ; L_{l 2}=$ $0.00618 \mathrm{H} ; \mathrm{NP}=2 ; P_{N}=2.2 \mathrm{KW} ; V_{N}=220 \mathrm{~V}$.

Controllers' parameters:

\section{TABLE I}

Controllers' constants and parameters.

\begin{tabular}{|c|c|c|c|c|}
\hline Specification & $\mathbf{S M C}_{d}$ & $\mathbf{S M C}_{q}$ & $\mathbf{P I}_{d}$ & $\mathbf{P I}_{q}$ \\
\hline$K_{P}$ & 5 & 10 & 25 & 25 \\
\hline$K_{I}$ & 10 & 10 & 15 & 15 \\
\hline$c_{\text {sn }}$ & $10^{-8}$ & $10^{-5}$ & - & - \\
\hline$K$ & 3 & 3 & - & - \\
\hline max & 50 & 50 & - & - \\
\hline min & -50 & -50 & - & - \\
\hline
\end{tabular}

\section{ACKNOWLEDGEMENT}

The authors would like to thank CAPES, FAPESP and $\mathrm{CNPq}$ for financial support.

\section{REFERENCES}

[1] G. Abad, J. López, M. Rodríguez, L. Marroyo, M. Rodríguez, and G. Iwanski. "Doubly Fed Induction
Machine: Modeling and Control for Wind Energy Generation Applications". John Wiley \& Sons, 2011.

[2] J. A. Baroudi, V. Dinavahi, and A. M. Knight. A review of power converter topologies for wind generators. Renewable Energy, 32:2369-2385, 2007.

[3] A.J. Netto, P.R. Barros, C.B. Jacobina, A.M.N. Lima, and E.R.C.v da Silva. Indirect field-oriented control of an induction motor by using closed-loop identification. In Industry Applications Conference. Fourtieth IAS Annual Meeting, 2005.

[4] A. Tapia, G. Tapia, J.X. Ostolaza, and J.R. Saenz. Modeling and control of a wind turbine driven doubly fed induction generator. IEEE Transactions on Energy Conversion, 18(2):194-204, Jun. 2003.

[5] B. Shen and B.-T. Ooi. Novel sensorless decoupled pq control of doubly-fed induction generator(dfig) based on phase locking to gamma-delta frame. In Power Electronics Specialists Conference, 2005.

[6] B. H. Chowdhury and S. Chellapilla. Double-fed induction generation control for variable speed wind power generation. Electric Power System Research, 2006.

[7] R. V. Jacomini, A. França, and E. Bim. Simulation and experimental studies on double-fed induction generator power control operating at subsynchronous operation speed. In Power Electronics and Drive Systems, 2009. 
[8] F. K. A. Lima, A. Luna, P. Rodriguez, E. H. Watanabe, and F. Blaabjerg. Rotor voltage dynamics in the doubly fed induction generator during grid faults. IEEE Trans. on Power Electronics, 1(1):118-130, Jan. 2010.

[9] V. F. Mendes, C.V. de Sousa, S. R. Silva, B. C. Rabelo, and W. Hofmann. Modeling and ride-through control of doubly fed induction generators during symmetrical voltage sags. IEEE Transactions on Energy Conversion, 26(4):1161 -1171, Dec. 2011.

[10] A. J. Sguarezi Filho, M. E. de oliveira Filho, and E. Ruppert. A predictive power control for wind energy. IEEE Transactions on Sustainable Energy, 2(2):97-105, 2011.

[11] C. Edwards and S.K. Spurgeon. "Sliding Mode Control: Theory And Applications". Taylor \& Francis systems and control book series, 1998.

[12] W. NAOUAR, E. Monmasson, A. Naassani, and I. Slama-Belkhodja. Fpga-based dynamic reconfiguration of sliding mode current controllers for synchronous machines. IEEE Transactions on Industrial Informatics, (99): $18-25,2012$.

[13] M. Rashid. "Power electronics circuits, devices and aplications". Pretince Hall, 2004.

[14] C. Lascu, I. Boldea, and F. Blaabjerg. Direct torque control of sensorless induction motor drives: a slidingmode approach. IEEE Transactions on Industry Applications, 25(2):582-590, march-april 2004.

[15] S.Z. Chen, N.C. Cheung, K.C. Wong, and J. Wu. Integral variable structure direct torque control of doubly fed induction generator. Renewable Power Generation, IET, 5(1):18 -25, Jan. 2011.

[16] J. Hu, H. Nian, B. Hu, Y. He, and Z.Q. Zhu. Direct active and reactive power regulation of dfig using slidingmode control approach. IEEE Transactions on Energy Conversion, 25(4):1028-1039, Dec. 2010.

[17] H. G. Jeong, W. S. Kim, K. B. Lee, B. C. Jeong, and S. H. Song. A sliding-mode approach to control the active and reactive powers for a dfig in wind turbines. In Power Electronics Specialists Conference, 2008.

[18] X. Zheng, W. Li, and W. Wang. High-order sliding mode controller for no-load cutting-in control in dfig wind power system. In Systems and Control in Aeronautics and Astronautics (ISSCAA), 2010 3rd International Symposium on, 2010.

[19] J. P. da Costa, H. Pinheiro, T. Degner, and G. Arnold. Robust controller for dfigs of grid-connected wind turbines. IEEE Transactions on Industrial Eletronics, 58(9):4023-4038, Sep 2011.

[20] W. Leonhard. "Control of Electrical Drives". SpringerVerlag Berlin Heidelberg New York Tokyo, 1985.

[21] M. V. Lazarini and E. Ruppert Filho. Induction motor control didactic set-up using sensorless and sliding mode dtc strategy. Eletrônica de Potência, 13(4):291-299, 2008.

[22] L-G Shiau and J.-L. Lin. Stability of sliding-mode current control for high performance induction motor position drives. Electric Power Applications, IEE Proceedings , 148(1):69-75, 2001.
[23] J. Hun and B. Wu. New integration algorithms for estimating motor flux over wide speed range. IEEE Trans. on Power Electronics, 13(5):969-977, September 1998.

[24] A. J. Sguarezi Filho and E. Ruppert Filho. The complex controller for three-phase induction motor direct torque control. Sba Controle e automação., 20(2):256-262, 2009.

\section{BIOGRAPHIES}

Filipe Sarmento Trindade received his bachelor degree in Electrical Engineering from Federal University of Pará (UFPa) and his Master degree from Campinas University in Brazil, respectively, in 2010 and 2013. His areas of interest are electric machinery, power electronics and machine drives.

Alfeu J. Sguarezi Filho received his bachelor degree in Electrical Engineering from Faculdade área 1, his Master degree and his $\mathrm{Ph}$. D. degree from Campinas University in Brazil, respectively in 2005, 2007 and 2010. He was working as researcher at Campinas University by FAPESP pos-doctoral program from 2010 to 2011. Now, he is a professor at Federal University of ABC - UFABC, in Santo André, Brazil, teaching in the areas of Electrical Machines, Power Electronics and Electrical Drives. His research interests are machine drives, doubly-fed induction generators, power control, and electrical power systems.

Rogério Vani Jacomini was born in Santa Barbara D' Oeste, Sao Paulo, Brazil, in 1979. Received the B.S. degree in electrical engineering from Salesian University Center of Sao Paulo, Brazil, in 2004, the M.S. and Ph. D. degree from State University of Campinas, Brazil, respectively in 2008 and 2012. Currently, he is working researcher at University of $A B C$ - UFABC, Brazil. His current research interest include $\mathrm{AC}$ drives and doubly fed induction machine.

Ernesto Ruppert Filho received his bachelor degree in Electrical Engineering and his Master and $\mathrm{PhD}$ degrees from Campinas University in Brazil, respectively in 1971, 1974 and 1983. From 1972 to 1978 he had been working at Electrical and Computer Engineering School of Campinas University as an Assistance Professor in the Electromechanical Energy Conversion area, from 1979 to 1983 he had been working for General Electric in Brazil designing large induction and synchronous motors and working as an Application Engineer dedicated to large motors and generators, from 1983 to 1989 he had been working for Vigesa Heavy Equipments in Brazil designig very large hydrogenerators and also performing commissionig testes in some hydro power plants in Brazil. From 1989 to 1992 he runned his own company dealing with electrical installations and from 1992 up to now he is working as Full Professor at the Electrical and Computer Engineering School of Campinas University, in Campinas, Brazil, researching and teaching in the areas of Electrical Machines, Power Electronics, Drives and Electrical Power Systems. 